\section{Depressão no Ciclo da Vida}

Lafer B, Almeida OP, Fráguas R Jr., Miguel EC (editores). ARTMED, Porto Alegre, 2000.

O livro organizado por Beny Lafer, Osvaldo P Almeida, Renério Fráguas Jr. e Eurípedes C. Miguel é um marco na psiquiatria brasileira. Traz pesquisadores brasileiros e internacionais demonstrando profundidade e atualizações em vários tópicos associados à depressão. São 26 capítulos, divididos em cinco partes: Conceito, quadro clínico e diagnóstico, Patogênese, Tópicos especiais, Tratamento, e uma última parte conclusiva, denominada Depressão no ciclo de vida: uma única doença?

A primeira parte - Conceito, quadro clínico e diagnóstico abrange o conceito e limites da depressão com dados epidemiológicos atuais e descrições clínicas por faixa etária: infância, adolescência e senectude. A depressão é um transtorno do humor grave freqüente, e ocorre em todas as faixas etárias, sendo que as taxas parecem estar aumentando entre jovens e idosos. Por razões ainda não totalmente esclarecidas, a depressão vem se tornando cada vez mais freqüente neste século. Talvez isso seja apenas o resultado de uma melhor identificação e de maior esclarecimento. Dados recentes do estudo epidemiológico norte-americano - "Epidemiologic Catchment Area Program", $30 \%$ dos entrevistados relataram já terem se sentido deprimidos por no mínimo duas semanas, e 5\% relataram já terem tido ao mesmo tempo um episódio de depressão. Distimia foi encontrada em 3\% da população. Com esses números, podemos calcular que existem no Brasil aproximadamente 54 milhões de pessoas que em um momento de suas vidas terão algum tipo de depressão, sendo que 7,5 milhões terão episódios agudos e graves, muitas com risco de suicídio.

Na segunda parte - Patogênese - são abordados com profundidade os temas relacionados a genética, neuroquímica, neuroimagem e teorias psicológicas. Essa parte marca uma mudança na abordagem da depressão. Apesar da depressão ter causas desconhecidas, atores genéticos, psicológicos, ambientais, anatomopatológicos e bioquímicos estão envolvidos na sua gênese e evolução, estando presentes em graus variáveis em cada indivíduo com depressão.

$\mathrm{O}$ fator genético-hereditário certamente está presente em muitos casos de forma clara. Em outros, podemos supor que ele não seja tão evidente. O que parece ser herdado é uma tendência para um funcionamento bioquímico anormal em algumas regiões cerebrais. Esse funcionamento anormal facilitaria que essas pessoas tivessem depressão. A grande maioria dos casos de depressão parece ser geneticamente transmitida e quimicamente produzida. A discussão se a depressão é psicológica ou biológica é igual à questão se qualquer doença é biológica ou psicológica. Por exemplo, uma úlcera duodenal é psicológica ou biológica? Estamos certos de que existem fatores biológicos e psicológicos em todas as doenças humanas. Em algumas, o fator biológico é determinante e os psicológicos, conseqüência.

Na terceira parte - Tópicos especiais -, diferentes temas re- lacionados à depressão são abordados: transtorno bipolar, distimia, depressão psicótica, depressão puerperal, suicídio e depressão associada a outras doenças. Os subtipos clássicos de depressão, com sintomas leves (distimia e ciclotimia) ou graves (depressão psicótica ou com risco de suicídio) têm apresentado avanços conceituais, diagnósticos e terapêuticos. A idéia de que certos tipos de personalidade pos-

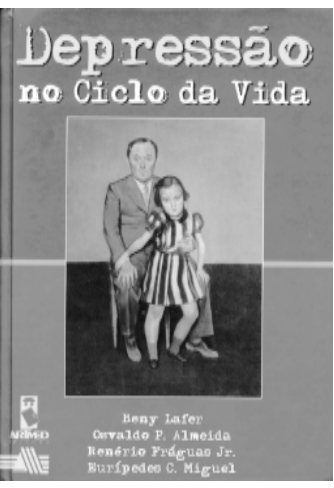
sam ser formas atenuadas ou "subsindrômicas" de transtornos do humor data dos psicopatologistas clássicos alemães do século XIX. Essa visão dimensional entre transtornos do humor, em que haveria um "continuиm" entre as formas subsindrômicas e a doença plena, tem ampla tradição na medicina. A hipótese do relacionamento dimensional entre transtornos de personalidade e do humor tem apresentado estudos longitudinais prospectivos e rigorosa descrição fenomenológica, com a observação da resposta terapêutica aos psicofármacos. Dessa forma, tem-se separado pacientes com transtorno de personalidade de base caracterológica (desenvolvimento) daqueles com uma base temperamental.

Na quarta parte - Tratamento -, os antidepressivos tricíclicos, os inibidores da monoaminoxidase e os inibidores seletivos da recaptação de serotonina são abordados de forma abrangente. Outros capítulos trazem a eletroconvulsoterapia, a terapia cognitivo-comportamental, o tratamento da depressão na infância, na adolescência e em idosos, e as opções de tratamento da depressão resistente. Nesse ponto, é demonstrado que os tratamentos farmacológicos não são opostos às diferentes formas de psicoterapia, pelo contrário, os dois tratamentos são complementares. Em diversas ocasiões, o medicamento fará com que o paciente se recupere e admita a necessidade de se tratar tanto com medicamentos de manutenção e/ou de prevenção quanto com psicoterapia que ampliará seu autoconhecimento e o ajudará na reintegração social e na retomada de sua individualidade.

A depressão, se não tratada corretamente, pode perdurar por muito tempo, com sério prejuízo à vida do paciente: trabalho, família e lazer ficam muito comprometidos, juntamente com um risco maior de suicídio. $\mathrm{O}$ tratamento bem-sucedido reduz esse período para 8 a 12 semanas. Entretanto, a depressão, ainda que responda bem ao tratamento instituído, pode recidivar e/ou cronificar. Tratamento medicamentoso constitui o fundamento da intervenção terapêutica para reduzir a duração e a intensidade dos sintomas do episódio atual e, principalmente, para prevenir sua recidiva.

Dois pontos fundamentais no tratamento com qualquer antidepressor são apresentados de forma clara: tempo correto de uso e dose adequada. Todo antidepressor apresenta um período de latência para o efeito terapêutico. Infelizmente, a única maneira que temos para saber se uma pessoa com depressão responderá favoravelmente ao medicamento é após o seu uso. Por isso, deve- 
mos sempre dar preferência à utilização de antidepressor que apresentou resposta favorável anteriormente naquele paciente.

Na parte conclusiva - Depressão no ciclo da vida: uma única doença? -, Eugene Paykel traz sua experiência quanto ao conceito, evolução e tratamento da depressão ao longo da história da psiquiatria e da história de vida de cada paciente. A depressão é um transtorno grave, que pode comprometer toda a vida familiar, laborativa e social do paciente. A depressão destrói famílias, carreiras e relacionamentos. O tratamento médico com uso de antidepressores e psicoterapia associada é fundamental. Os preconceitos existentes em relação a ter uma doença mental só podem ser suplantados com o conhecimento e a informação.
"Depressão no ciclo de vida" é um livro didático e abrangente, podendo ser útil inclusive para pacientes e familiares que queiram se informar de maneira aprofundada no conhecimento de depressão. É uma fonte segura de atualização, com colaboradores experientes, o que a torna indispensável para todo profissional que lida com pacientes com transtorno de humor.

Antonio Egidio Nardi

Coordenador do Laboratório de Pânico \& Respiração Instituto de Psiquiatria Universidade Federal do Rio de Janeiro

\section{Errata}

No rodapé do Artigo Especial “Consenso sobre a Síndrome de Abstinência do Álcool” (Rev Bras Psiquiatr 2000;22(2)62-71), leia-se Maria do Perpétuo S. Souza Nóbrega (SP) onde se lê Perpétua Nóbrega. 